\title{
Uterine Corpus Lipoleiomyoma
}

National Cancer Institute

\section{Source}

National Cancer Institute. Uterine Corpus Lipoleiomyoma. NCI Thesaurus. Code C40168.

A rare morphologic variant of uterine corpus leiomyoma characterized by the presence of scattered islands of mature adipocytes within the smooth muscle neoplasm. 